\title{
Relationship between clinical and electromyographic findings and exposure to solvents, in shoe and leather workers
}

\author{
E. BUIATTI, ${ }^{1}$ S. CECCHINI, ${ }^{1}$ O. RONCHI, ${ }^{2}$ P. DOLARA, ${ }^{3}$ AND \\ G. BULGARELLI
}

From the ${ }^{1}$ Centro di Medicina sociale della Provincia di Firenze, ${ }^{2}$ Clinica delle malattie nervose e mentali and ${ }^{3}$ Istituto di Farmacologia dell 'Università di Firenze, ${ }^{4}$ Centro di Calcolo della Regione Emilia Romagna, Florence, Italy

ABSTRACT A very high prevalence of polyneuropathy was observed in shoe and leather workers from the area of Florence. In addition, normal workers showed abnormally low maximal nerve motor conduction velocity. A linear decrease of motor conduction velocity was observed as a function of age and of the length of exposure to solvents. The worker population showed a steeper decrease with age than controls. A higher prevalence of polyneuropathy was observed when the amount of glue used by each worker per day was higher, and when the air volume of the plant was smaller. The subjective symptoms most frequently associated with polyneuropathy were muscle spasms, leg weakness and pain, and arm paresthesiae. Cases of polyneuropathy were more frequent in the workers exposed to solvents and in the older age group. A solvent aetiology of the disease is suggested, and glue substitution and proper hygienic conditions are recommended.

Many reports have been published concerning the occurrence of polyneuropathy in shoe and leather workers from various countries (Sobue et al., 1968; Vigliani, 1968; Inoue et al., 1970; Abbritti et al., 1976). It was suggested at first that the polyneuropathy could be related to exposure to triorthocresylphosphate (TOCP), an agent known to be highly neurotoxic (Crepet et al., 1968; Chauderon and Léveque 1969). It was later demonstrated that TOCP was seldom present in glues and leather (Abbritti et al., 1976), and a strict correlation was shown between exposure to low-boiling-point solvents (Bourret et al., 1968), n-hexane (Sobue et al., 1968; Inoue et al., 1970; Herskowitz et al., 1971) and the occurrence of polyneuropathies. The toxicity of $n$-hexane and methyl n-butyl ketone on the peripheral nervous system has been shown experimentally also in the rat (Kurita, 1967; Mendell et al., 1974). In this paper we report the results of a study involving about 350 leather and shoe workers in the area of Florence, in which clinical and electromyographic findings were related to exposure to solvents.

Received for publication 5 July 1977

Accepted for publication 11 August 1977

\section{Materials and methods}

Workers from 31 plants in the area of Florence were studied. The number of workers per plant varied from 6 to 515. The glues were analysed chemically in order to exclude the presence of TOCP and to determine the kind of solvent used. Gas chromatographic analysis showed that the solvent composition of different glues was very variable in different plants and different seasons of the year. The solvents were found to vary in the following range (expressed as the percentage of total solvent): n-hexane, 40-99.5\%; aliphatic branched or linear low boiling point hydrocarbons, 7-54\%; ethyl acetate, $15-44 \%$; trichloroethylene, $0.42-45.3 \%$; n-heptane, $7-10 \%$. Traces below $1 \%$ of benzene, toluol and xylol were found.

The subjects were apparently healthy workers, and no acute polyneuropathy was found during the study. The workers were assessed for objective signs of peripheral nervous system involvement (muscle tone, tendon reflexes, muscle wasting, sensory disorders), and any subjective symptomatology was recorded. For the electromyographic measurements a 1510B HP electromyograph was used, to which a two-channel OTE Biomedica 1172 averager was connected. Dr Ronchi used the 168 
apparatus throughout the whole study. The extensor digitorum brevis and abductor pollicis brevis muscles were examined in all cases, and conduction velocity was measured with Adrian and Bronk needle electrodes. For the measurements of maximum motor conduction velocity (MCV) of the median nerve the potentials were registered at the level of the abductor pollicis brevis.

A supramaximal square wave pulse of $100-200$ $\mu$ sec was applied to the median nerve at the level of the elbow and of the wrist. The ratio between the difference in latency at the two levels and the distance was calculated. For the sensitive velocity measurements a supramaximal square wave of 50 $\mu \mathrm{sec}$ was applied to the thumb, and the latency of the nerve conduction was measured at the wrist and at the elbow.

The same procedure was used with the lateral popliteal nerve. Recording electrodes were placed in the extensor digitorum brevis muscle and the stimulating electrodes were placed on the lateral popliteal nerve at the level of the knee and of the ankle.

The control electromyographical MCV data were obtained from normal subjects examined in the neurological department during neurological screening of the normal population. Care was taken to exclude people who had previous contact with neurotoxic compounds.

Conduction velocity was considered to be in the pathological range when it was lower than the $5 \%$ fiducial limits in the normal population of the same age. For an electromyographical diagnosis of polyneuropathy other aspects of the tracings were considered. The presence of spontaneous activity, polyphasic and irregular potentials, and a reduced interference pattern were all taken into account, together with alteration in size of motor response and of sensory action potentials.

Laboratory investigations were carried out in order to exclude the presence of other diseases with neurotoxic signs. Workers with a previous history of contact with neurotoxic compounds other than solvents were excluded.

Statistical analysis of the data was accomplished using a series of computer programs of the BMD statistical computer library (Dixon, 1971), on a CII 10070 computer.

\section{Results}

RELATIONSHIP BETWEEN THE OCCURRENCE OF POLYNEUROPATHY, AND SEX, EXPOSURE TO SOLVENTS, AND AGE

No significant difference in the occurrence of polyneuropathy was found between sexes (Table 1). This discrepancy with other reports (Abbritti et al., 1976) can be explained by the fact that workers of both sexes were uniformly distributed in different sections of each industry. The occurrence of polyneuropathy was significantly higher in the group of workers exposed to the action of solvents (Table 1). We have considered in this group also the workers who were not actually gluing, but were near the gluing area. A significantly higher incidence of polyneuropathy was observed in the group of workers who used more than $1.3 \mathrm{~kg}$ of glue/day (Table 1), and in those factories in which the air volume was less than $40 \mathrm{~m}^{3} /$ worker. In this analysis we have considered only the factories with one production hall and a homogeneous environment. It was not possible, for each subject, to obtain detailed information about all the aspects of the production environment. Hence, the total numbers involved in the analysis (Table 1) are variable.

Fig. 1 shows the frequency distribution of normal and polyneuropathic workers according to age. The incidence of polyneuropathy was significantly higher in the group aged $40-70$ years (46 positive cases out of 120 subjects older than 40 , and 40 positive cases out of 218 subjects younger than 40 . $\left(\chi^{2}=16.32\right.$; one degree of freedom (df); $\left.P<0.005\right)$.

Table 1 Relationships between the incidence of polyneuropathy, sex, exposure to solvents, and plant ventilation

\begin{tabular}{|c|c|c|c|c|c|c|c|c|}
\hline \multirow[t]{2}{*}{ Subjects } & \multicolumn{2}{|l|}{ Sex } & \multicolumn{2}{|c|}{ Solvent exposure } & \multicolumn{2}{|c|}{ Glue used/worker/day $(\mathrm{kg})$} & \multicolumn{2}{|c|}{ Air/worker $\left(m^{3}\right)$} \\
\hline & Male & Female & Yes & No & $<1 \cdot 3$ & $>1 \cdot 3$ & $<40$ & $>40$ \\
\hline Polyneuropathic & $\underset{(27 \%) \dagger}{4 .} \stackrel{\Delta}{(48 \%)}$ & $\underset{(24 \%) \dagger}{44 \%}$ & $\begin{array}{l}70(83 \%) \\
(29 \%)\end{array}$ & $\begin{array}{l}14(17 \%) \\
(17 \%)\end{array}$ & $\begin{array}{l}17(44 \%) \\
(39 \%)\end{array}$ & $\begin{array}{l}22(56 \%) \\
(20 \%)\end{array}$ & $\begin{array}{l}27(69 \%) \\
(32 \%)\end{array}$ & $\begin{array}{l}12(31 \%) \\
(17 \%)\end{array}$ \\
\hline Normal & $\begin{array}{l}\triangle \\
113(44 \%) \\
(73 \%) \dagger \\
x^{2}=0.39 ;\end{array}$ & $\begin{array}{l}142(56 \%) \\
(76 \%) \dagger \\
\mid f=1\end{array}$ & $\begin{array}{l}173(72 \%) \\
(71 \%) \\
x^{2}=4 \cdot 4^{*} ;\end{array}$ & $\begin{array}{l}68(18 \%) \\
(83 \%) \\
f=1\end{array}$ & $\begin{array}{l}27(24 \%) \\
(61 \%) \\
x^{2}=5.61\end{array}$ & $\begin{array}{l}87(76 \%) \\
(80 \%) \\
\text { df }=1\end{array}$ & $\begin{array}{l}56(49 \%) \\
(68 \%) \\
x^{2}=4 \cdot 73\end{array}$ & $\begin{array}{l}58(51 \%) \\
(83 \%) \\
\text { df }=1\end{array}$ \\
\hline
\end{tabular}

$\triangle \Delta$ row percentages, indicating the \% distribution of the two alternatives for each variable, in the group of polyneuropathic ( $\Delta$ ) and in the group of normal workers $(\triangle)$.

+Column percentages, indicating the \% distribution of the cases of polyneuropathy and normality for each variable considered. The air space for each worker was calculated by dividing the total air space in the plant by the number of workers.

*Significant difference $(P<0.05)$ in the incidence of polyneuropathy between the two alternatives for each variable. 


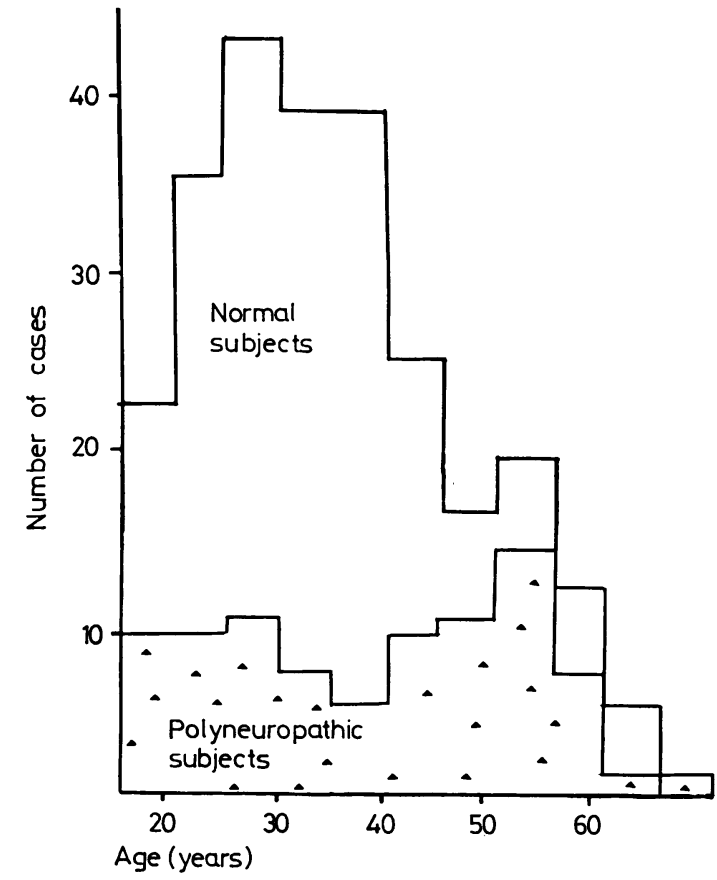

Fig. 1 Frequency distribution of normal workers and of workers affected by polyneuropathy, as a function of age (in years). The frequencies were calculated for each five-year group.

If the distribution of polyneuropathy is shown as a function of the duration of the exposure to solvents (Fig. 2), the incidence of the illness is progressively greater with more prolonged exposure.

\section{RELATIONSHIP BETWEEN MOTOR NERVE} MCV, AGE, AND EXPOSURE TO SOLVENTS It is known that the MCV of motor nerves is linearly related to age (La Fratta and Smith, 1964; Nielsen, 1973). We have therefore studied the relationship between age and the MCV of the lateral popliteal nerve in a group of workers exposed to solvents, and in a control group of non-exposed workers (Fig. 3). The regression lines were significant both for non-exposed workers $(F=4.74 ; \quad d f=78$; $P<0.05)$ and for exposed workers $(F=24.65$; $\mathrm{df}=241 ; \mathrm{P}<0.01$ ). The null hypothesis of no difference between the two groups was rejected comparing the two populations by analysis of covariance $(\mathrm{F}=13.55 ; \mathrm{df}=321 ; \mathrm{P}<0.01)$. The slopes of the two lines also differ significantly $(\mathrm{F}=13.56 ; \mathrm{df}=321 ; \mathrm{P}<0.01)$. We can conclude that exposure to solvents increases the physiological lowering of conduction velocity with age.

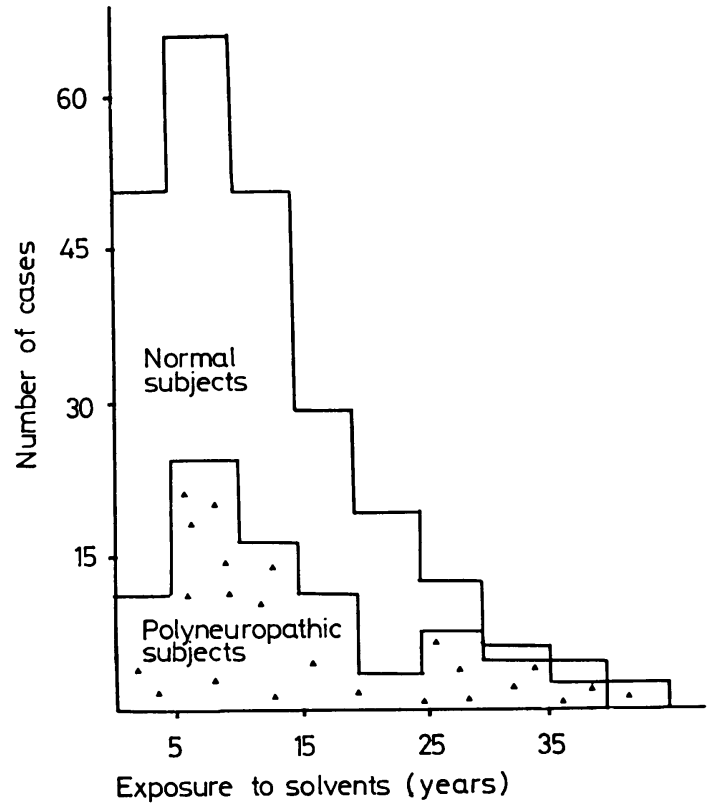

Fig. 2 Frequency distribution of normal workers and workers affected by polyneuropathy as a function of the duration of exposure to solvents (in years).

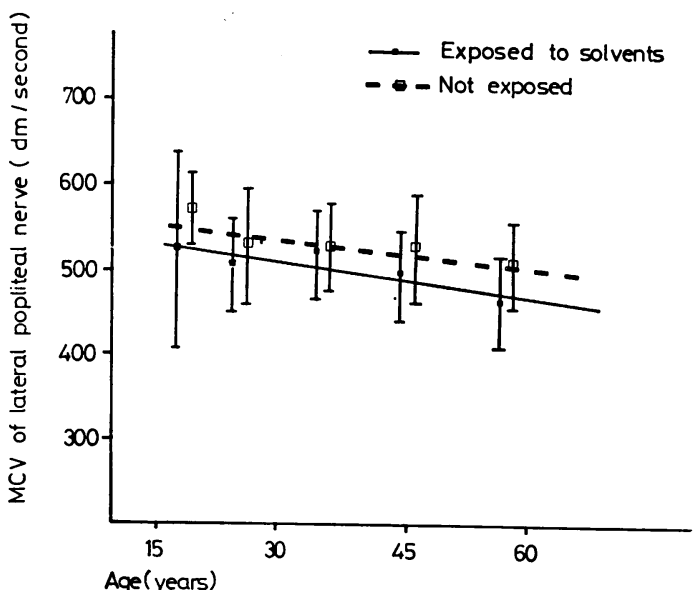

Fig. 3 Correlation between maximal conduction velocity (MCV) of a motor nerve (the lateral popliteal nerve) and age, in workers exposed and not exposed to solvents. The regression lines and the means $\pm 5 \%$ fiducial limits are shown. The individual values, and not the means, were used for regression analysis. The equations of the regression lines for non-exposed workers $(n=80): y=-1 \cdot 1875 x+571 \cdot 3 ;$ for exposed workers $(n=243): y=-1 \cdot 3731 x+551 \cdot 9$. 
Fig. 3 and the subsequent Figures show the means $\pm 5 \%$ fiducial limits with the different regression lines. These were drawn because the variance of the different age groups was not homogeneous, and we wanted to demonstrate the variability of the experimental data in each group. In addition this clearly shows the overlap of MCV in each age group.

If we analyse the decrease in MCV as a function of age in the normal population, in a group of normal workers and in a group of workers affected by polyneuropathy (Fig. 4) we find, as expected, that the second and the third group differ significantly, the slope of the third regression line being significantly steeper. In fact the regression lines were all significant (Normal populations: $F=5.69$; df $=140 ; P<0.05$. Normal workers: $F=12.65$; df $=237 ; \quad P<0.01$. Polyneuropathic workers: $\mathrm{F}=7.77 ; \quad \mathrm{df}=82 ; \mathrm{P}<0.01)$. By analysis of covariance a significant difference was found between normal and polyneuropathic workers $(\mathrm{F}=72.9 ; \mathrm{df}=321 ; \mathrm{P}<0.01)$, and between the normal population and the normal workers $(F=25.33 ; \mathrm{df}=3.79 ; \mathrm{P}<0.01)$. The slope of the regression line of normal workers was found to be statistically different from that of polyneuropathic workers $(\mathrm{F}=25.33$; $\mathrm{df}=321 ; \mathrm{P}<0.01)$.

It is interesting that the group of normal workers differs from the normal population. This implies

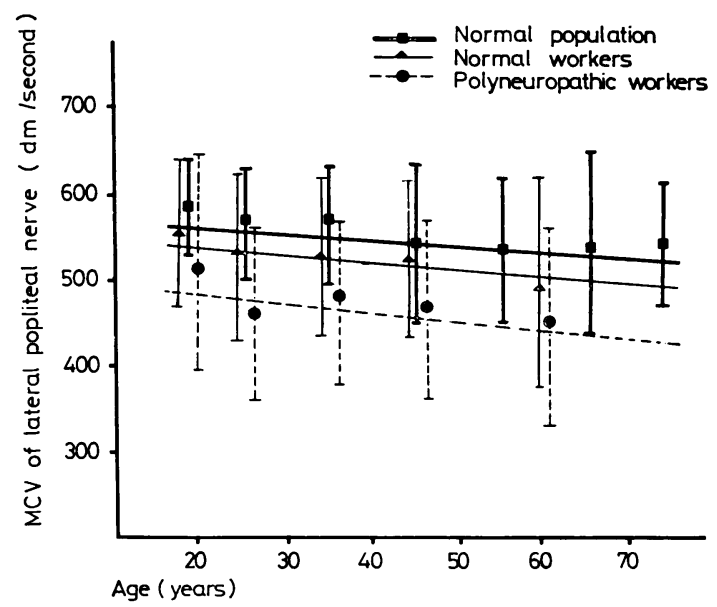

Fig. 4 Correlation between MCV of the lateral popliteal nerve and age in the normal population, in normal workers and in workers affected by polyneuropathy. The regression equations for normal workers $(n=239): y=-0.9552 x+557 \cdot 9 ;$ for the normal population $(n=142): y=-0.536 x+568 \cdot 8 ;$ for polyneuropathic workers $(n=84): y=-1 \cdot 084 x+507 \cdot 5$. that it is possible to detect the neurotoxic action of the solvents also in the 'normal' worker population. The same results were obtained at the level of the median nerve. We must emphasise, however, that although statistical differences in the MCV were found for the different populations, the marked overlapping of fiducial limits indicates that the $\mathrm{MCV}$ is not a reliable criterion for the diagnosis of polyneuropathy, at least when taken in isolation.

The relationship between the duration of the exposure to solvents and the MCV is shown in Fig. 5 . A linear correlation was found between these two variables; this correlation may be explicable in part by the change in MCV with age, already discussed. We therefore selected a group of 43 workers, all aged 50-55 years, for analysis of the relationship between duration of exposure and MCV without the confounding effect of age. The results depicted in Fig. 5 show that duration of exposure is definitely related to the MCV, although the slope of the regression line is much closer to unity $(-1.077)$ than is the slope of the mixed age population $(-1 \cdot 324)$.

The variation of conduction velocity was analysed as a function of the duration of exposure to solvents in the group of normal workers and in the group of polyneuropathic workers (Fig. 6). The slope of the second group is significantly steeper $(F=84.05$; $\mathrm{df}=321 ; \mathrm{P}<0.01)$. This shows that the polyneuropathic workers have a greater susceptibility to the action of solvents as a function of the duration of exposure. The same correlation was tested for

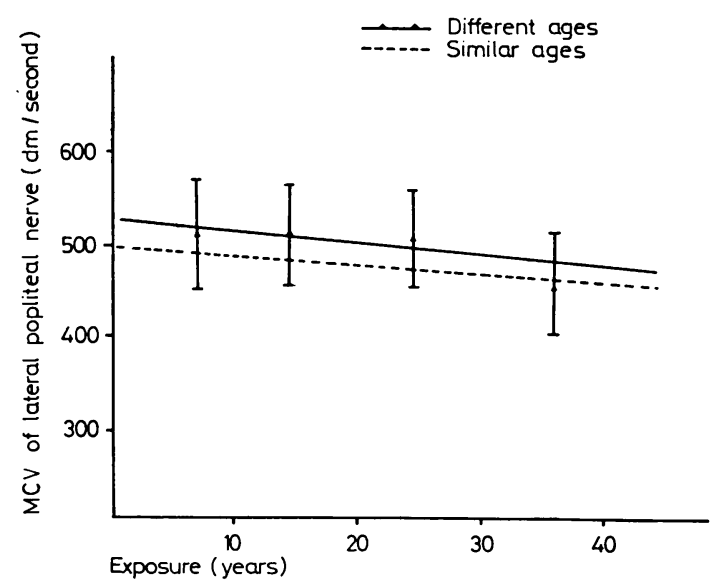

Fig. 5 Correlation between MCV of the lateral popliteal nerve and duration of exposure in a group of workers of different ages and in a group of similar ages (50-55 years). The regression equations for dissimilar age $(n=323): y=-1 \cdot 3246 x+525 \cdot 5(r=-0 \cdot 21) ;$ for similar age $(n=43): y=-1 \cdot 077 x+500 \cdot 29(r=-0 \cdot 21)$. 


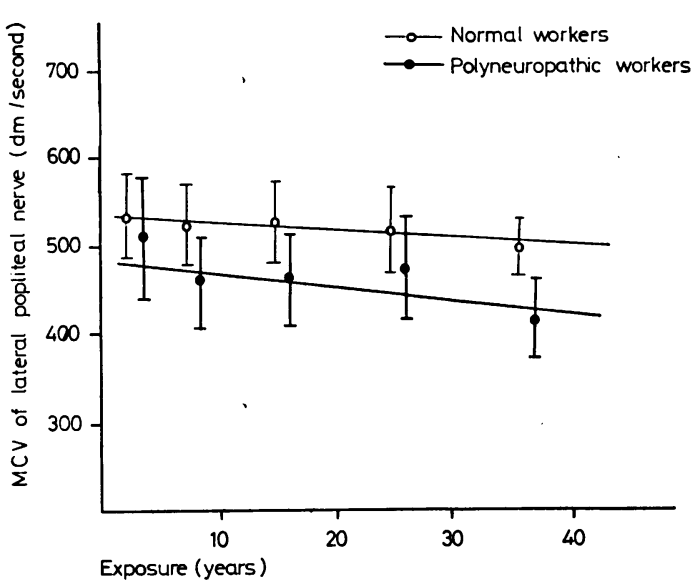

Fig. 6 Correlation between MCV of the lateral popliteal nerve as a function of the duration of exposure to solvents in a group of normal workers and in polyneuropathic workers. The equations of the regression lines for normal workers $(n=239)$ :

$y=-0.8206 x+534 \cdot 9 ;$ for workers affected by

polyneuropathy $(n=84): y=-1 \cdot 567 x+485 \cdot 7$.

sensory nerve conduction velocity at the level of the median nerve, but no difference was found.

The correlation between sensory action potential amplitude and exposure to solvents was not examined during this study.

\section{RELATIONSHIP BETWEEN SUBJECTIVE}

SYMPTOMS AND POLYNEUROPATHY

The correlation between the occurrence of subjective symptoms and polyneuropathy was studied (Table 2). Only four symptoms were significantly associated with polyneuropathy (lower limb weakness, lower limb pain, upper limb paresthesiae, muscle spasm). Thirteen subjects with completely symptomless polyneuropathy were found in the group of workers exposed to the solvents for a prolonged period.

\section{Discussion}

It is evident from the preceding results that a very high prevalence of polyneuropathy was observed among shoe and leather workers of the Florentine area ( 85 out of $340,25 \%$ ). We must emphasise that normal workers also showed an abnormally low MCV compared with that of a control population of the same age. The high variability and the overlapping of the fiducial limits suggests, however, that a reduction of $\mathrm{MCV}$ in itself is not sufficient for a diagnosis of polyneuropathy. Other abnormalities of the electromyographic tracings and neurological signs of peripheral nervous system involvement must be considered. Of the subjective symptoms, those most significantly associated with polyneuropathy are limb paresthesiae and spasms. A personal history of long exposure to solvents is highly predictive, as demonstrated by the finding of polyneuropathy in asymptomatic workers.

The incidence of polyneuropathy increases when the amount of glue/worker/day is greater than $1.3 \mathrm{~kg}$ and ventilation is poor. This strongly suggests that the disease is caused by volatile solvents. The very variable glue composition does not permit one to draw a correlation between the concentration of a definite solvent and the occurrence of polyneuropathy. We are able, however, to exclude TOCP as a causative factor in the workers we have examined, because TOCP was not found in any of the glues used.

The highest incidence of polyneuropathy was in the oldest workers. It must be stressed, however, that only apparently healthy workers were examined, and the acute polyneuropathic syndromes seen in the young was not the object of the study.

The conclusion that can be drawn is that solvents used in the leather and shoe industry are neurotoxic, and that more hygienic conditions, or changes in the glues used, are necessary to avoid serious hazards to the workers' health.

Table 2 Relationship between subjective symptoms and polyneuropathy

\begin{tabular}{|c|c|c|c|c|c|c|c|c|}
\hline \multirow[t]{2}{*}{ Subiects } & \multicolumn{8}{|l|}{ Symptoms } \\
\hline & $\begin{array}{l}\text { Asthenia in } \\
\text { lower limbs }\end{array}$ & No asthenia & $\begin{array}{l}\text { Pain in lower } \\
\text { limbs }\end{array}$ & No pain & $\begin{array}{l}\text { Paresthesiae } \\
\text { in upper limbs }\end{array}$ & $\begin{array}{l}\text { No } \\
\text { paresthesiae }\end{array}$ & $\begin{array}{l}\text { Muscle } \\
\text { spasms }\end{array}$ & No spasms \\
\hline Polyneuropathic & $\begin{array}{l}11(14 \%) \\
(41 \%)\end{array}$ & $\begin{array}{l}65(86 \%) \\
(22 \%)\end{array}$ & $\begin{array}{l}36(47 \%) \\
(31 \%)\end{array}$ & $\begin{array}{l}40(53 \%) \\
(20 \%)\end{array}$ & $\begin{array}{l}7(11 \%) \\
(50 \%)\end{array}$ & $\begin{array}{l}59(89 \%) \\
(24 \%)\end{array}$ & $\begin{array}{l}28(42 \%) \\
(36 \%)\end{array}$ & $\begin{array}{l}38(58 \%) \\
(21 \%)\end{array}$ \\
\hline Normal & $\begin{array}{l}16(7 \%) \\
(59 \%) \\
x^{2}=4 \cdot 55^{*} ;\end{array}$ & $\begin{array}{l}225(93 \%) \\
(78 \%) \\
=1\end{array}$ & $\begin{array}{l}80(33 \%) \\
(69 \%) \\
x^{2}=4.69 * ; \mathrm{df}\end{array}$ & $\begin{array}{l}160(67 \%) \\
(80 \%) \\
=1\end{array}$ & $\begin{array}{l}7(4 \%) \\
(50 \%) \\
x^{2}=4.53 * ; \text { df }\end{array}$ & $\begin{array}{l}183(96 \%) \\
(76 \%) \\
=1\end{array}$ & $\begin{array}{l}50(26 \%) \\
(64 \%) \\
x^{2}=5.9 * ;\end{array}$ & $\begin{array}{l}140(74 \%) \\
(79 \%) \\
\text { If }=1\end{array}$ \\
\hline
\end{tabular}

Row and column percentages as in Table 1

*Significant difference $(\mathrm{P}<0.05)$ 


\section{References}

Abbritti, G., Siracusa, A., Cianchetti, C., Coli, C. A., Curradi, F., Perticoni, G. F., and De Rosa, F. (1976) Shoemakers' polyneuropathy in Italy: the aetiological problem. British Journal of Industrial Medicine 33, 92-99.

Bourret, J., Viallier, J., Tolot, F., and Robillard, J. (1968). Polynévrites par exposition simultanée au trichlorétilène et à l'essence. Archives des Maladies Professionelles, 29, 228-236.

Chauderon, J., and Léveque, J. (1969). Treize cas d'intoxication professionelle par le tri-cresyl-phosphate en milieu artisanal. Archives des Maladies Professionelles, 30, 716-719.

Crepet, M., Gaffuri, E., and Picotti, G. (1968). La patologia da triarilfosfati nell'industria calzaturiera. Lavoro Umano, 20, 443-453.

Dixon, W. J. (1971). BMD Biomedical Computer Programs. University of California Press: Berkeley, Los Angeles, and London.

Herskowitz, A., Ishii, N., and Schaumburg, H. (1971). n-Hexane neuropathy: a syndrome occurring as a result of industrial exposure. New England Journal of Medicine, 285, 82-85.

Inoue, T., Takeuchi, Y., Takeuchi, S., Yamada, S., Suzuki, H.,
Matsushita, T., Miyagaki, H., Maeda, K., and Matsumoto, T. (1970). A health survey on vinyl sandal manufacturers with a high incidence of $\mathrm{n}$-hexane intoxication. Japanese Journal of Industrial Health, 12, 73-84.

Kurita, H. (1967). Experimental studies on the effects of n-hexane to albino rats. Japanese Journal of Industrial Health, 9, 672-677.

La Fratta, C. W., and Smith, O. H. (1964). A study of the relationship of motor nerve conduction velocity in the adult to age, sex, and handedness. Archives of Physical Medicine and Rehabilitation, 45, 407-412.

Mendell, J. R., Saida, K., Jackson, D. B., Gardner, R. W., Hetland, L., Marks, B., O'Neil, J., Couri, D., Allen, N., Chrisman, S., and Ganansia, M. F. (1974). Toxic polyneuropathy produced by methyl n-butyl ketone. Science, 185, 787-789.

Nielsen, K. (1973). Sensory and motor nerve conduction in the median nerve in normal subjects. Acta Medica Scandinavica, 194, 435-443.

Sobue, I., Yamamura, Y., Ando, K., Iida, M., and Takanayagi, T. (1968). n-Hexane polyneuropathy. Clinical Neurology (Tokyo), 8, 393-403.

Vigliani, E. C. (1968). Osservazioni cliniche su 47 casi di polineuriti motorie manifestatesi in operai lavoranti con mastici e collanti. Lavoro Umano, 20, 448-449. 